\title{
Heat Transfer Analysis During Quenching of Plate Roller in Quenching Machine Using CFD
}

\author{
Sanskar Singh \\ Research Scholar \\ Department of Mechanical \\ Engineering \\ College of Engineering Science \& \\ Technology \\ Lucknow, India. \\ shivpandit0121@gmail.com
}

\author{
Vandana Singh \\ Research Scholar \\ Department of Mechanical \\ Engineering \\ College of Engineering Science \& \\ Technology \\ Lucknow, India
}

\author{
Kajol Kumari \\ Assistant Professor \\ Department of Mechanical \\ Engineering \\ College of Engineering Science \& \\ Technology \\ Lucknow, India
}

\begin{abstract}
:
A computational fluid dynamics analysis of steel plate using volume of fluid multiphase model moving at different velocity i.e. 0.1 to $1 \mathrm{~m} / \mathrm{sec}$ with $0.1 \mathrm{~m} / \mathrm{sec}$ interval. From the above concluding points it has been observed that heat flux increased for the steel plate moving at $0.1 \mathrm{~m} / \mathrm{sec}$. During quenching process the surface heat transfer coefficient increases at first. And when plate surface temperature is nearly $420 \mathrm{oC}$, surface heat transfer coefficients reach the maximum value of about $15000 \mathrm{~W} /\left(\mathrm{m}^{2} \mathrm{~K}\right)$. And then, the calculated heat transfer coefficients are applied to analyze plate temperature field of different thicknesses, and the difference between the calculated and measured temperature is less than $35 \%$.
\end{abstract}

\section{INTRODUCTION}

Quenching is a no stationary thermodynamic process the aim of which is to attain the required level of superficial hardness as well as adequate hardness distribution on the cross-section of a hardened work piece, with minimum deformation and size change. These two requirements are opposite to each other: A higher quenching intensity to achieve greater depth of hardening increases deformation and size change. This shows the complexity of the quenching process and the need to optimize quenching parameters as well as to control the quenching intensity as far as possible. To do this, one has to know, from the one side, the hardenability of the steel grade in question, and from the other side, the dynamic of heat extraction from the work piece. From the first moment when a work piece is immersed in a quenching, three different processes start and develop simultaneously, as shown in Fig. 1. Each of these three processes has its own dynamic. It is especially important to know that the transformation of the microstructure does not start on the whole cross-section simultaneously, but gradually from the surface to the core, only when a particular point attains the temperature A1 because in the temperature region from the austenitizing temperature to A1, there is no transformation of the microstructure, This fact makes it possible (at least for bigger cross-sections) to intentionally change the heat extraction dynamic, i.e., to control the quenching process.

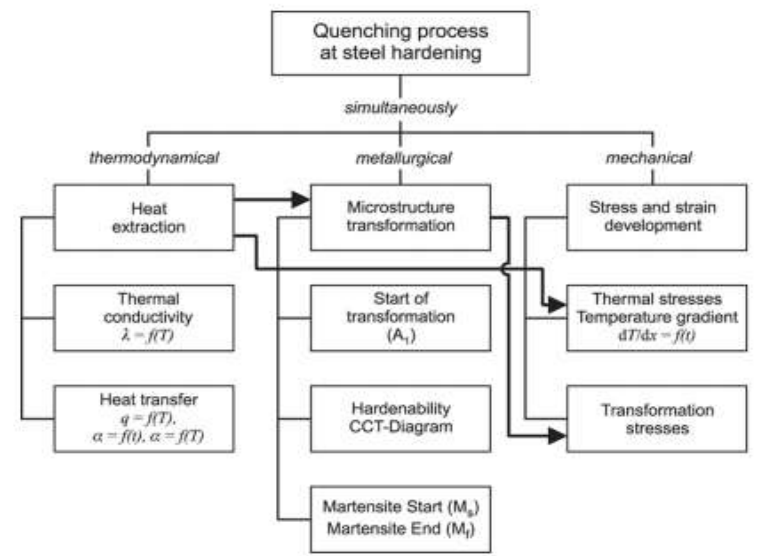

Figure 1.- Simultaneous mutually dependent processes at quenching.

\section{LITERATURE REVIEW}

Božidar Liščić et al. [1] The aim of this article is to discuss the measures to control the dynamic of heat extraction by changing some parameters during quenching. This is possible for workpieces of not too small a cross-section size, because transformation of the microstructure proceeds gradually from the surface to the core only when a particular point attains the temperature A 1. Differences between calculation of the temperature dependent heat transfer coefficient (HTC) for laboratory 
specimens and for real workpieces, taking into account the damping effect, the time lag, and the thermocouple response time, have been discussed. High Pressure Gas Quenching (HPGQ) in vacuum furnaces is especially prone to changing some parameters during quenching.

Hala Salman Hasan et al. [2] in this paper presented heat transfer coefficients for quenching in water have been measured as a function of temperature using steel probes for a variety of iron alloys. The coefficients were derived from measured cooling curves combined with calculated heat-capacities. The resulting data were then used to calculate cooling curves using the finite volume method for a large steel sample and these curves have been demonstrated to be consistent with measured values for the large sample. The work should prove useful in the heat treatment of the steels studied, some of which are in the development stage.

Rayyan Mamuda Dodo, et al. [3] This study investigates the possibility of multi-objective optimization in the trans esterification of mahogany seed oil (MSO). The Taguchi method together with Grey relational analysis (GRA) was used to maximize both percent fatty acid methyl ester (FAME) yield and heat transfer coefficient (HTC). It was found that methanol to oil molar ratio was the factor that contributed the most in obtaining high percent FAME (ester) yield and HTC. Employing the following conditions: $32.6 \mathrm{wt} \%$ methanol (9:1 methanol to oil molar ratio), $0.5 \mathrm{wt} \%$ catalyst, $60{ }^{\circ} \mathrm{C}$ temperature and $300 \mathrm{rpm}$ agitation was found to offer an improved percent ester yield and HTC. A confirmatory test resulted in an ester yield of $90.1 \%$ and HTC up to $153.0 \mathrm{~W} / \mathrm{m} 2 \mathrm{~K}$. The structure of the optimized trans esterified mahogany seed oil (TM) was confirmed by FTIR analysis. In the event of comparison, TM, raw mahogany seed oil (FM) and SAE40 were analyzed by cooling curve analyses.

\section{OBJECTIVE}

Aim of this articles to simulate the impingement of a water droplet on a superheated wall by solving conservation equations of mass, momentum and energy. The level set method is applied for interface tracking and appropriate jump conditions are imposed at the interface by the ghost fluid method. The effect of moving velocity of steel roller during quenching process on the heat removal is studied.

\section{METHODOLOGY}

The running speed of steel plate varies from 0.1 $\mathrm{m} / \mathrm{sec}$ to $1 \mathrm{~m} / \mathrm{sec}$ with $0.1 \mathrm{~m} / \mathrm{sec}$ interval, and the surface temperature of hot steel plate is taken as $850{ }^{\circ} \mathrm{C}$ and it is assume that the incoming temperature uniformly distributed over the heated steel plate. The thermal properties of the steel plate are implicit to be constant with temperature for convenience because the present study is focused on the for the boiling heat transfer on the steel plate.

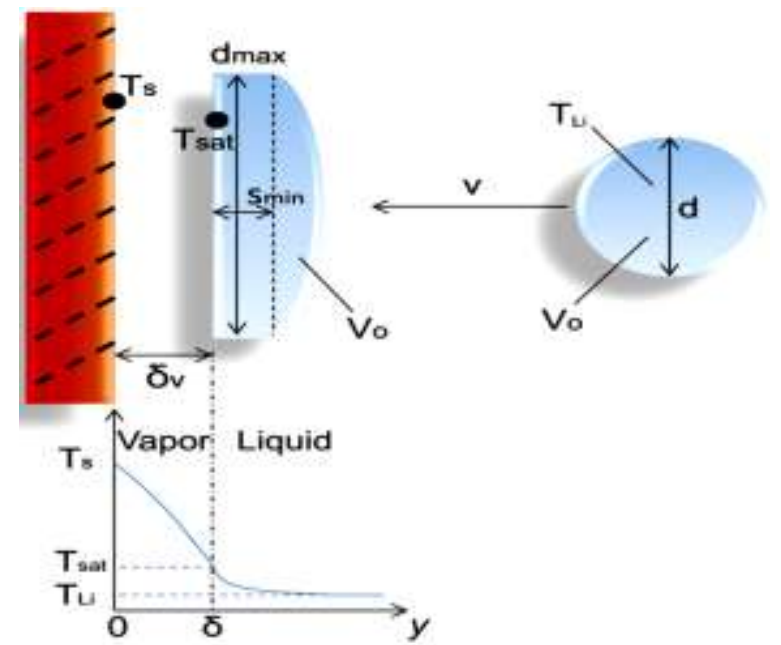

Figure 1: Temperature profile of an impacting droplet above the Leiden frost temperature

When a single droplet reaches the hot surface, a contact temperature will be established which is only slightly below the surface temperature of the metal. This contact temperature depends on the ratio of the heat penetration coefficient of the metal and the liquid. The heat penetration coefficient is the product of thermal conductivity $(\lambda)$, density ( $\rho$ ) and specific heat capacity (c). Since metal has a significantly higher value than water, the contact temperature is closer to the metal temperature. As the contact temperature is considerably higher than the boiling temperature, the water evaporates immediately. Therefore, the droplet can be considered to expand almost without friction on a vapor cushion. In Figure 1 the temperature profile in a bounced droplet is shown in principle with the maximum expansion. The surface of the droplet to the metal side is assumed to be at boiling temperature. Therefore, the heat transfer in turn depends on the temperature gradient in the fluid.

Flow and temperature fields are calculated with the initially guessed effective thermal conductivity, $\mathrm{k}_{\text {eff }}$ on the plate. Normally the value for water is used as an initial guess. Using the wall heat flux, and the wall temperature ( $\left.\mathrm{T}_{\text {wall }}\right)$ obtained by the previous step the thickness of film layer, $\delta_{\text {film }}$ can be estimated with Equation describing the thermal diffusion in the steam layer.

$$
q_{\text {wall }}=K_{\text {steam }} \frac{T_{\text {wall }}-100\left[{ }^{\circ} \mathrm{C}\right]}{\delta_{\text {film }}}
$$

Where the constant $100^{\circ} \mathrm{C}$ means that the interfacial temperature between the steam layer and the liquid water is nearly the saturation temperature for atmospheric pressure.

$K_{\text {steam }}$ is the thermal conductivity of steam. From continuity for the heat flux at the interface between the steam layer and liquid water, the cell centered temperature; $T_{\text {cell }}$ can be recalculated with the following equation: 


$$
q_{\text {wall }}=K_{\text {water }} \frac{100\left[{ }^{\circ} C\right]-T_{\text {cell }}}{\delta_{\text {cell }}-\delta_{\text {film }}}
$$

The heat flux at the interface is equal to the wall heat flux, given the assumption that the heat from a plate is completely transported to the cell in the normal direction. $K_{\text {water }}$ is the thermal conductivity of the liquid water, and $\delta_{\text {cell }}$ the distance from a plate wall to a cell centered point. The effective thermal conductivity which was used for flow field calculation

$$
q_{\text {wall }}=K_{\text {eff }, \text { new }} \frac{T_{\text {wall }}-T_{\text {cell }}}{\delta_{\text {cell }}}
$$

When the temperature of a liquid at a specified pressure is raised to the saturation temperature $T_{\text {sat }}$ at that pressure, boiling occurs. Although boiling and condensation exhibit some unique features, they are considered to be forms of convective heat transfer due to fluid motion. Boiling and condensation differ from other forms of convection in that they depend on the latent heat of vaporization $h_{f g}$ of the fluid and the surface tension at the liquid vapor interface. Under equilibrium condition the temperature remains constant during phase change at fix pressure.

Energy balance analysis and accuracy:

In order to calculate the heat flux for a specific position on the metal disc, an energy balance is performed as follows:

$$
-\rho \times c \times s \times \frac{\Delta T}{\Delta t}=\dot{q}_{s p}+\dot{q}_{\lambda}+\dot{q}_{R}
$$

Where $\rho, c$, and $s$ are the density, specific heat capacity, and the thickness of the metal disc respectively. The change of the stored enthalpy in the disc caused by temperature decrease is equal to the sum of the heat transfer by the spray ${ }^{\circ} q_{s p}$, radial conduction ${ }^{\circ} q_{\lambda}$, radiation $\cdot q_{R}$, and free convection $\mathrm{q} \alpha$.

$$
\dot{q}_{s p}=h \times\left(T_{s}-T_{s p}\right)
$$

Where $\mathrm{q}_{\mathrm{sp}}, \mathrm{h}$, and $\mathrm{T}_{\mathrm{s}}$ are the heat flux, heat transfer coefficient, and surface temperature of the metal sample, respectively.

Heat flux is calculated using the fourier differential equation for cylindrical coordinates

$$
\dot{q}_{\lambda}=-s \times \lambda \times \frac{1}{r} \times \frac{\partial}{\partial r}\left(r \times \frac{\partial T}{\partial r}\right)
$$

Where $s$ is the thickness of the disc, $\lambda$ is the conductivity of material, and $r$ is the radius. The gradient $\partial \mathrm{T} / \partial \mathrm{r}$ is known from the temperature measurement.

In multiphase model select the Volume of Fluid multiphase model and Enable the Implicit Body Force formulation. Define the primary phase as vapor and secondary phase as liquid. To determine the temperature distribution need to on energy equation. Defining of material property, the working fluid is taken as mixture of water liquid \& water vapor and hot surface as steel, for the outlet boundary condition the gauge pressure needs to be set as zero. Under Thermal Conditions, hot surface temperature range of $400-850{ }^{\circ} \mathrm{C}$. This indicates superheat with respect to the saturation temperature. Under Discretization, select PRESTO! For pressure, and QUICK for Momentum and Energy.

\section{RESULT AND DISCUSSION}

The impact of water droplet on a uniform thickness water film with the impact velocity of $38 \mathrm{~m} / \mathrm{s}$ is simulated. The film thickness decreases with the fluid speed. For the impact velocity of $38 \mathrm{~m} / \mathrm{s}$ (assume wind and droplet have the same speed), we assume a uniform film thickness of 2 $\mu \mathrm{m}$.

The thin film splashing mechanism is significantly different from dry surface splashing: when the droplet impacts on the thin film, it expels the film from the surface and pushes it move outward.

\section{}
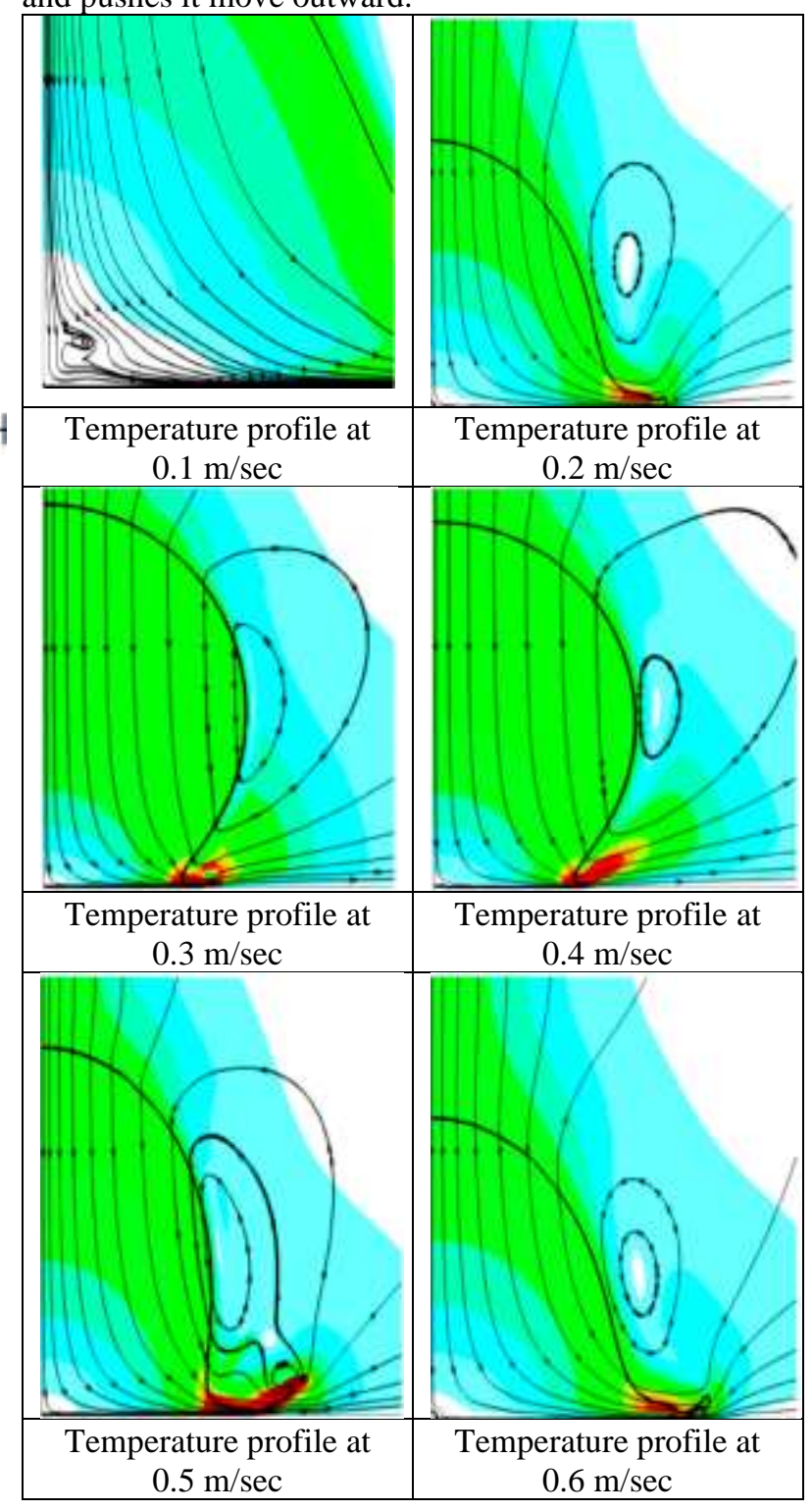


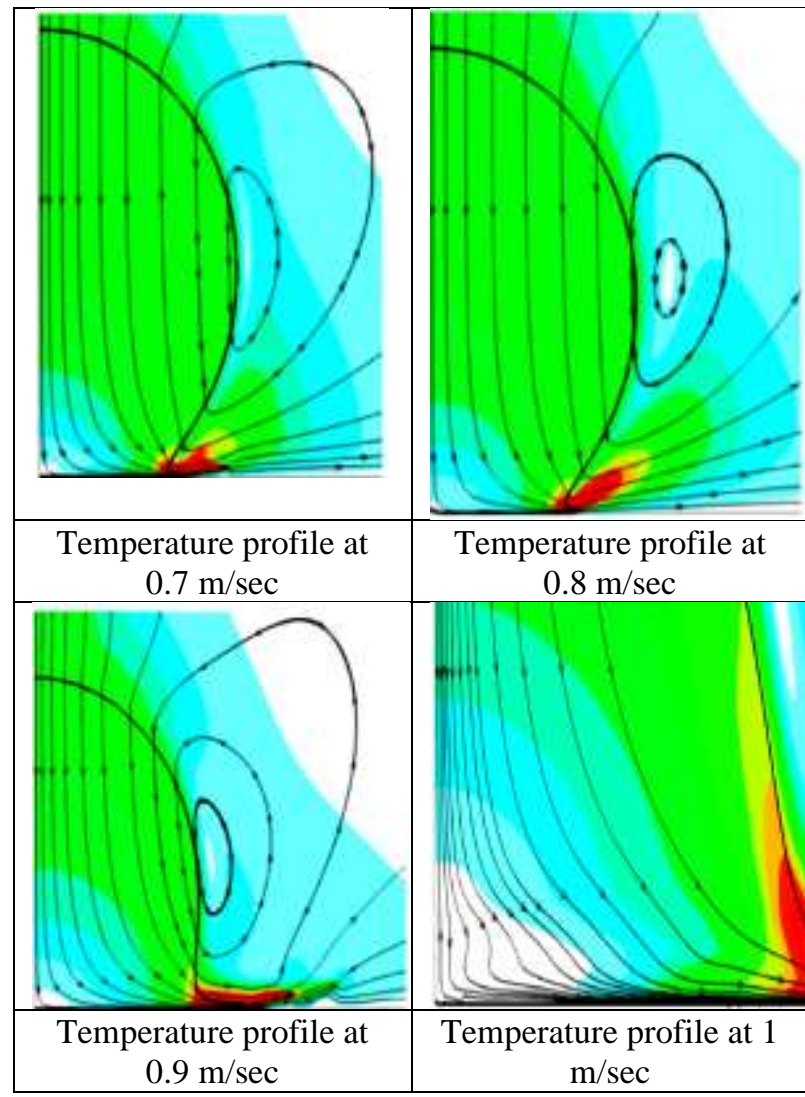

Figure 02: Variation of temperature profile for different velocity ranging from $0.1 \mathrm{~m} / \mathrm{sec}$ to $1 \mathrm{~m} / \mathrm{sec}$

Temperature distribution from hot surface to liquid phase has been obtained for different time interval as shown in below contours diagram. The contours diagrams of formation of vapor above the heated steel surface are plotted on XY plane. The generation of bubbles starts moving upwards, the formation of vapor bubbles and collapse more rapidly because the thermal boundary is very thin and the fluid temperature around the bubbles almost equal to the saturation temperature.

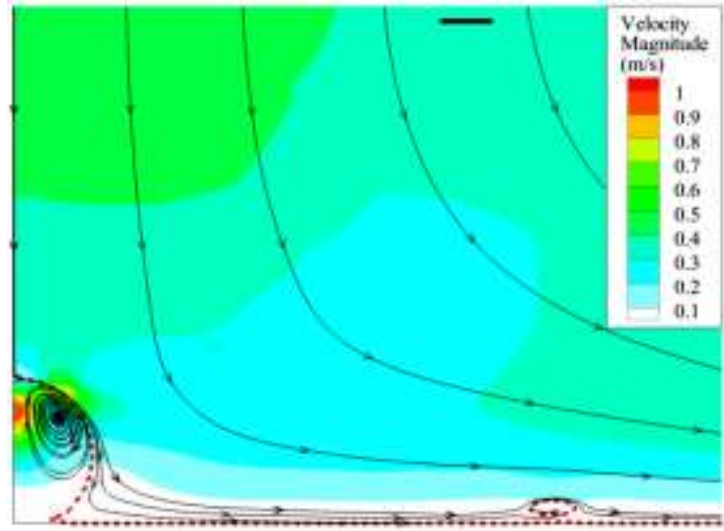

Figure 03: Flow of cooling water over the heated plate Figure 3 show the liquid flows around the air bubble and flow near the wall has extremely low velocity due to viscous effect. For drop impact at $\rho_{\text {air }}=0.245 \mathrm{~kg} / \mathrm{m}^{3}$ recirculation is observed but it is formed at a much later stage.

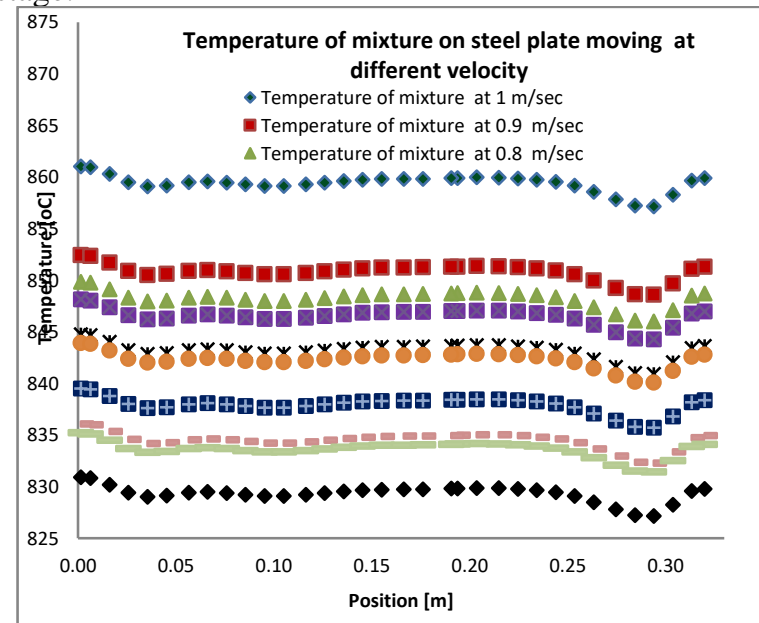

Figure 4: Temperature of mixture on steel plate moving at different velocity

\section{CONCLUSION}

Due to the boiling mass exchange occurring at the vapor liquid interface bubbles of steam are periodically produced and emitted upward such a regime is known as film boiling. A computational fluid dynamics analysis of steel plate using VOF multiphase model moving at different velocity i.e. 0.1 to $1 \mathrm{~m} / \mathrm{sec}$. velocity plate is taken only $0.2 \mathrm{~m} / \mathrm{s}$ to $0.5 \mathrm{~m} / \mathrm{s}$. remove heat flux discussion and the discuss mainly heat transfer coefficient effect. During quenching process the surface heat transfer coefficient increases at first. And when plate surface temperature is nearly $420^{\circ} \mathrm{C}$, surface heat transfer coefficients reach the maximum value of about $15000 \mathrm{~W} /\left(\mathrm{m}^{2} \mathrm{~K}\right)$. And then, the calculated heat transfer coefficients are applied to analyze plate temperature field of different thicknesses, and the difference between the calculated and measured temperature is less than $35 \%$.

\section{REFERENCES}

1. Božidar Liščić "Heat Transfer Control during Quenching” DOI: 10.1080/104269109029 17694.

2. Hala Salman Hasan, Mathew James Peet "Heat transfer coefficients during quenching of steels" DOI: 10.1007/s00231-010-0721-4 March 2011

3. Rayyan Mamuda Dodo, T. Ause "Multi-response optimization of transesterification parameters of mahogany seed oil using grey relational analysis in Taguchi method for quenching application" DOI: 10.1016/j.heliyon.2019.e02167 August 2019

4. J.M.Salaa L.M., LópezGonzález "Improvement of a chain-hardening furnace by computational fluid dynamics (CFD) simulation" Volume 81, Issue 3, July 2005, Pages 260-276

5. Sergey Makarov, A. M. Lipanov "Numerical Investigation of Heat Transfer During the Cooling of a Metal Cylinder by a Flow of a Gas-Liquid 
Medium in an Annular Channel" DOI:

10.1007/s10891-019-02009-2 August 2019

6. Tiago Augusto Moreira, Alex Roger Almeida Colmanetti "Heat transfer coefficient: a review of measurement techniques" DOI: 10.1007/s40430-

019-1763-2 May 2019 